\title{
KARAKTERISTIK INTENSITAS RADIOAKTIVITAS BATUAN DAN SEDIMEN TERPILIH DI PANTAI SEDAU, KALIMANTAN BARAT
}

\section{RADIOACTIVE INTENSITY CHARACTERISTICS OF SELECTED ROCK AND SEDIMENT ON SEDAU COAST, WEST KALIMANTAN}

\author{
Noor Cahyo Dwi Aryanto ${ }^{1 *}$, Lili Sarmili ${ }^{1}$, Emmy Suparka $^{2}$, dan Haryadi Permana ${ }^{3}$ \\ ${ }^{1}$ Puslitbang Geologi Kelautan, Jl. Dr. Junjunan No.236, Bandung-40174, Indonesia \\ ${ }^{2}$ Fakultas Ilmu Teknologi Kebumian, ITB, Jl. Ganesha No. 10, Bandung-40132, Indonesia \\ ${ }^{3}$ Pusat Penelitian Geoteknologi LIPI, Jl.Sangkuriang, Bandung-40135, Indonesia \\ *E-mail: cahyo@mgi.esdm.go.id / noor_aryanto@yahoo.com
}

Naskah diterima: 14 September 2015, direvisi: 2 Oktober 2015, disetujui: 15 Oktober 2015

\begin{abstract}
ABSTRAK
Intensitas pancaran unsur radioaktif berdasarkan data aktivitas batuan dan aktivitas pancaran B serbuk di Pantai Sedau dilakukan menggunakan metode analisis Spektrometer Gamma dan alat cacah $B$ terhadap sembilan contoh sedimen dan batuan. Intensitas radioaktif batuan memperlihatkan kisaran $\mathrm{U}_{238}$ dari $0,1202 \pm 0,008 \mathrm{~Bq} / 25 \mathrm{gr}$ hingga $0,4348 \pm 0,005$ $\mathrm{Bq} / 25 \mathrm{gr} ; \mathrm{Th}_{232}$ 0,0768 $\pm 0,005 \mathrm{~Bq} / 25 \mathrm{gr}$ hingga 0,4812 $\pm 0,015 \mathrm{~Bq} / 25 \mathrm{gr}$; sedangkan intensitas gross gammanya berkisar dari 1,0503 $\pm 0,029 \mathrm{~Bq} / 25 \mathrm{gr}$ hingga 5,6433 $\pm 0,273 \mathrm{~Bq} / 25 \mathrm{gr}$. Semua contoh yang memiliki intensitas unsur radioaktif untuk aktivitas batuan tinggi berasal dari batuan yang sama (monzogranit), yaitu di lokasi SKP08-04. Hasil yang sama pada pancaran $B$ serbuknya yang memperlihatkan aktivitas $B$ gross tertinggi juga terjadi di lokasi SKP08-04 pada batuan monzogranit dengan intensitas paparan 0,370 $\pm 0,025 \mathrm{~Bq} / 25 \mathrm{gr}$. Berdasarkan pengamatan petrografi, monzogranit di SKP08-04 memperlihatkan pelimpahan feldspar dengan kondisi yang relatif belum teralterasi sedangkan berdasarkan analisis geokimia memperlihatkan afinitas berupa seri kalk-alkali yang tinggi potasium.
\end{abstract}

Kata kunci: intensitas pancaran radioaktif, aktivitas batuan, paparan serbuk, monzogranit, Pantai Sedau

\section{ABSTRACT}

The intensity of the radioactive elements based on the rock activity data and $\beta$ powder emission activity on Sedau Coast were done using Gamma Spectrometer analysis method and $\beta$ detector to the nine samples of sediment and rocks. Radioactive intensity of $U_{238}$ in rocks showed a range from $0.1202 \pm 0.008 \mathrm{~Bq} / 25 \mathrm{gr}$ to $0.4348 \pm 0.005 \mathrm{~Bq} / 25 \mathrm{gr} ; \mathrm{Th}_{232} 0.0768 \pm$ $0.005 \mathrm{~Bq} / 25 \mathrm{gr}$ to $0.4812 \pm 0.015 \mathrm{~Bq} / 25 \mathrm{gr}$; while the gross gamma intensity ranged from $1.0503 \pm 0.029 \mathrm{~Bq} / 25 \mathrm{gr}$ to $5.6433 \pm 0.273 \mathrm{~Bq} / 25 \mathrm{gr}$. All the sample that has high intensity of radioactive element, occurs in the same rock (monzogranite) which is from samples in location 
SKP08-04. The same results in the emission of $\beta$ powder, which showed the highest gross $\beta$ activity also occurs in the rocks monzogranite (SKP08-04) with exposure intensity was $0.370 \pm$ 0.025 Bq/25gr. Based on petrographic observations, monzogranite in SKP08-04 showed the presence of abundant feldspar with the condition which relatively not altered, whereas the affinity based on geochemical analysis showed a calc-alkaline series of high potassium.

Keywords: radioactive intensity, rocks activity and powder exposure, monzogranite, Sedau coastal

\section{PENDAHULUAN}

Penelitian ini dimaksudkan untuk mengetahui keterkaitan kandungan dan intensitas radioaktivitas batuan terhadap karakteristik fisika dan kimiawi batuan, meliputi mineral penyusun, kondisi batuan, serta sifat afinitasnya. Granitoid di Pantai Sedau tersingkap di sekitar Tanjung Bajau hingga Tanjung Gondol pantai barat Singkawang ${ }^{[1,2]}$. Geologi regional di bagian utara Kalimantan (Malaysia dan Brunei) dibagi dalam tiga zona utama tektonik, dari barat laut hingga tenggara ${ }^{[3]}$ masing-masing adalah zona Miri, Siburajang, dan Kuching. Zona Kuching menandai tepian utara Sundaland. Volkanik Piyabung paleogen dan Intrusi Sintang Neogen ${ }^{[4]}$ adalah batuanbatuan magmatik di zona ini. Batas selatan dari zona Kuching ditandai oleh sesar yang berarah barat-timur yang memisahkan Cekungan Kutai di utara dari Cekungan Barito di selatan ${ }^{[5]}$.

Secara geografis lokasi penelitian berada pada koordinat $108^{\circ} 48^{\prime} \mathrm{BT}-108^{\circ} 51^{\prime} \mathrm{BT}$ dan $0^{\circ} 48^{\prime} \mathrm{LU}-0^{\circ} 51$ ' $\mathrm{LU}$, dan terletak $\pm 145 \mathrm{~km}$ arah utara dari Kota Pontianak yang secara administratif masuk ke dalam Kota dan Kabupaten Singkawang, Provinsi Kalimantan Barat. Daerah penelitian terletak di sisi barat Kalimantan Barat, di sebelah timur berbatasan dengan Kabupaten Bengkayang, di barat dan utaranya berbatasan dengan Laut Natuna, sedangkan perbatasan di selatannya dengan Kabupaten Mempawah.

Berdasarkan peta geologi lembar Singkawang (Gambar 1) $)^{[6]}$, stratigrafi regional daerah penelitian tersusun oleh beberapa satuan batuan (Gambar 2), dari tua ke muda adalah batuan gunung api Raya (Klr) banyak membentuk perbukitan terjal dan pulau-pulau dengan tebing curam di lepas pantai yang berumur Kapur; Granodiorit Mensibau (Klm) secara luas membentuk Batolit Singkawang, cenderung merupakan semenanjung bagian barat laut, terpisahkan dari Batolit Schwaner yang luas dan umumnya mendasari Kalimantan barat daya; serta Batuan Terobosan Sintang (Toms) yang muncul sebagai stok dan sumbat sub-gunung api. Semua batuan beku tersebut ditindih endapan Aluvium. Kuarter terdiri atas endapan Aluvium Terbiku (Qat) - aluvium dataran banjir dan rawa (Qa) serta endapan litoral Resen (Qc). Secara fisiografi, daratan Singkawang terdiri atas suatu zona pantai, dataran aluvial, dan undak pasir putih di barat, serta pebukitan menggelombang rendah yang meningkat sampai pebukitan curam yang terisolasi di timur. 


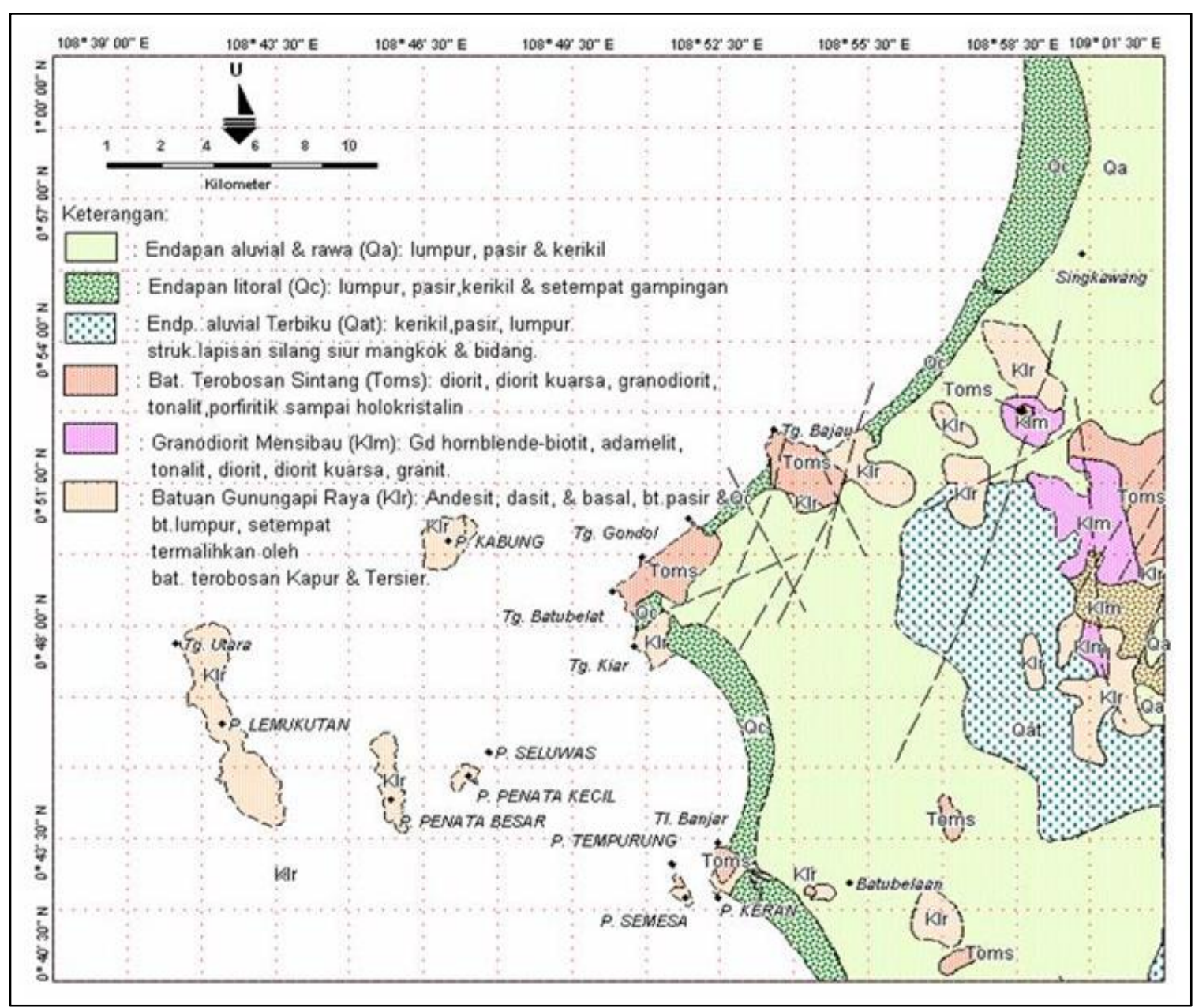

Gambar 1. Peta geologi daerah penelitian ${ }^{[6]}$.

\section{METODOLOGI}

Pengambilan contoh sedimen pantai dan batuan dengan menggunakan bor tangan dan palu geologi sedangkan pengambilan contoh sedimen dasar laut menggunakan grab sampler dan penginti jatuh bebas (gravity corer $)^{[7]}$. Analisis unsur radioaktif dilakukan di laboratorium BATAN Yogyakarta. Peralatan yang digunakan unit Spektrometer $\gamma$ dengan detektor $\mathrm{Ge}(\mathrm{Li})$, data akuisisi Maestro II; unit alat cacah $\beta$ dengan detektor GM; lumpang stainless steel; mixer buatan Spec; ayakan Tyler merk Karlkob ukuran 100 mesh; dan timbangan analitik buatan OHAUS GT 410. Langkah-langkah preparasi dan prosedur kerja, seperti di bawah ini ${ }^{[8]}$ :
Preparasi cuplikan dan standar:

- Masing-masing cuplikan ditumbuk dengan alat lumpang stainless steel

- Cuplikan halus disaring dengan ayakan Tyler dengan ukuran 100 mesh

- Cuplikan dihomogenkan menggunakan alat mixer buatan Spec selama 30 menit

- Masing-masing cuplikan dan standar primer (Standar IAEA 315) ditimbang seberat 25 gram untuk pencacahan dengan spektrometer $\alpha$ dan 1 gram untuk pencacahan proses $\beta$ dalam wadah cuplikan plastik dan diberi kode (KB untuk contoh batuan dari Pulau Kabung; SKP: untuk contoh batuan berasal dari Pantai Singkawang; BT: untuk contoh sedimen pantai berdasarkan pengambilan 
bor tangan; SKWL: contoh sedimen dasar laut)

- Cuplikan siap dianalisis.

Pencacahan dan Rumus Perhitungan Spektrometer Gamma $(\gamma)$ :

- Masing-masing cuplikan dan standar dicacah dengan meletakkan cuplikan pada jarak $2 \mathrm{~cm}$ di atas detektor kemudian dicacah selama 3600 detik. Setiap selesai pencacahan simpan masing-masing file spektrum pencacahan dalam komputer.

- Penentuan ROI (Region of Interest) puncak spectra dilakukan untuk memperoleh data Area Net. Identifikasi kuantitatif U-238 digunakan puncak spectra tenaga $\mathrm{Pb}-214$ pada $352 \mathrm{keV}$ sedangkan Th-232 digunakan puncak tenaga Ti-208 pada $510 \mathrm{keV}$.

- Aktivitas cuplikan setelah dibagi waktu cacah diperoleh dari data Area Net.

- Aktivitas latar ditentukan dengan pencacahan tanpa cuplikan.

- Pencacahan Gross $\gamma$ untuk penentuan aktivitas gross $\gamma$ (effisiensi, = 7,29\%).

- Rumus perhitungan aktivitas cuplikan:

Aktivitas Rad $_{\text {Cupl }}=\frac{\text { AreaNet }_{\text {Cupl }}}{\text { AreaNet Std }_{\text {Selivitas }}^{\text {Std }}} \times \frac{\text { Akt }_{40}}{40} \mathrm{~Bq} 25 \mathrm{gram}$

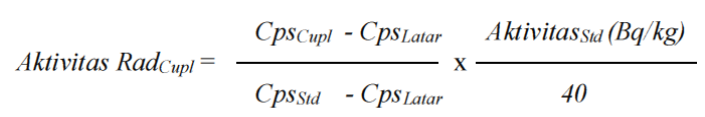

Untuk $\mathrm{U}_{-238}: \mathrm{Cps}_{\mathrm{Blk}}=0,0033$, Aktivitas ${ }_{\mathrm{Std}}=$ 17,6 Bq/kg. Untuk Th-232: $\mathrm{Cps}_{\mathrm{Blk}}=0,0053$, Aktivitas $_{\text {Std }}=25,6 \mathrm{~Bq} / \mathrm{kg}$.

Rumus penghitungan gross $\gamma$ :

Aktivitas gross $\gamma=\frac{100}{7,2865} \times C_{\text {S }}$ Cupl $B q / 25 \mathrm{gr}$

\section{Pencacahan Gross Beta ( $\beta$ )}

- Perangkat catu daya dihidupkan dan tegangannya dinaikkan sedikit demi sedikit hingga mencapai tegangan 1150 volt.

- Latar/cuplikan/sumber standar/cuplikan standar dimasukkan ke bawah detektor GM. Pencacahan dilakukan dengan waktu 20 menit, diulang beberapa kali dan diambil dua hasil pencacahan yang selisihnya maksimm 10.

- Efisiensi alat cacah ditentukan dengan KCL Merck. Hasil perhitungan efisiensi sebesar $8,11 \%$.

- Rumus perhitungan aktivitas gross $\beta$

$$
\text { Aktv. gross } \quad \boldsymbol{\beta}=\frac{{ }_{\text {ps }} \text { (upl }-C p s_{\text {Latar }}}{\text { E. Berat cuplikan }}=\ldots \ldots \ldots \ldots . . . . B q / g r
$$

\section{Pengujian menggunakan ICP}

\section{Preparasi Sampel:}

- Sampel ditimbang 0,10 gram ke dalam cawan teflon.

- $\mathrm{HNO}_{3}$ ultra pure $60 \%$, HF p.a $40 \%$, dan $\mathrm{HClO}_{4}$ p.a $60 \%$ masing-masing sebanyak $6 \mathrm{~mL}$ ditambahkan dengan menggunakan pipet volume.

- Campuran dipanaskan pada hotplate hingga mencapai suhu $200^{\circ} \mathrm{C}$ sampai sesaat sebelum kering.

- $\mathrm{HNO}_{3}$ ultra pure $60 \%$ sebanyak $5 \mathrm{~mL}$ ditambahkan sambil dipanaskan pada hotplate dengan suhu $150^{\circ} \mathrm{C}$.

- Sampel diangkat dan dinginkan pada suhu ruang.

- Sampel dilarutkan di dalam labu ukur 50 mL dengan ultra pure water.

- Larutan induk dipindahkan ke dalam botol plastik. 


\section{Persiapan Analisis}

- Larutan induk sebanyak $1 \mathrm{~mL}$ dimasukkan ke dalam labu ukur 10 mL.

- Larutan Be 1 ppm dan larutan Bi 1 ppm masing-masing ditambahkan sebanyak 0,1 $\mathrm{mL}$, kemudian batasnya ditandai dengan $\mathrm{HNO}_{3} 2 \%$ (larutan kerja).

- Larutan sampel dimasukkan ke dalam vial plastik khusus ICP untuk diuji.

- Larutan siap diuji.

\section{HASIL DAN PEMBAHASAN}

\section{Karakteristik fisik}

Berdasarkan pengambilan beberapa contoh batuan (Gambar 2) dan hasil pengamatan megaskopis batuan granitoid di sisi timur Tanjung Bajau (SKP08-04) dicirikan dengan equigranular, berwarna abuabu terang hingga kecoklatan, yang mencerminkan kelimpahan felspar (keabuan) bersama-sama dengan kuarsa (putih - abuabu). Mineral mafik didominasi biotit terdapat sebagai bercak-bercak (patches) (Gambar 3). Biotit merupakan mineral penting untuk penentuan umur batuan dan untuk mengetahui sejarah temperatur pembentukan batuan $^{[9]}$.

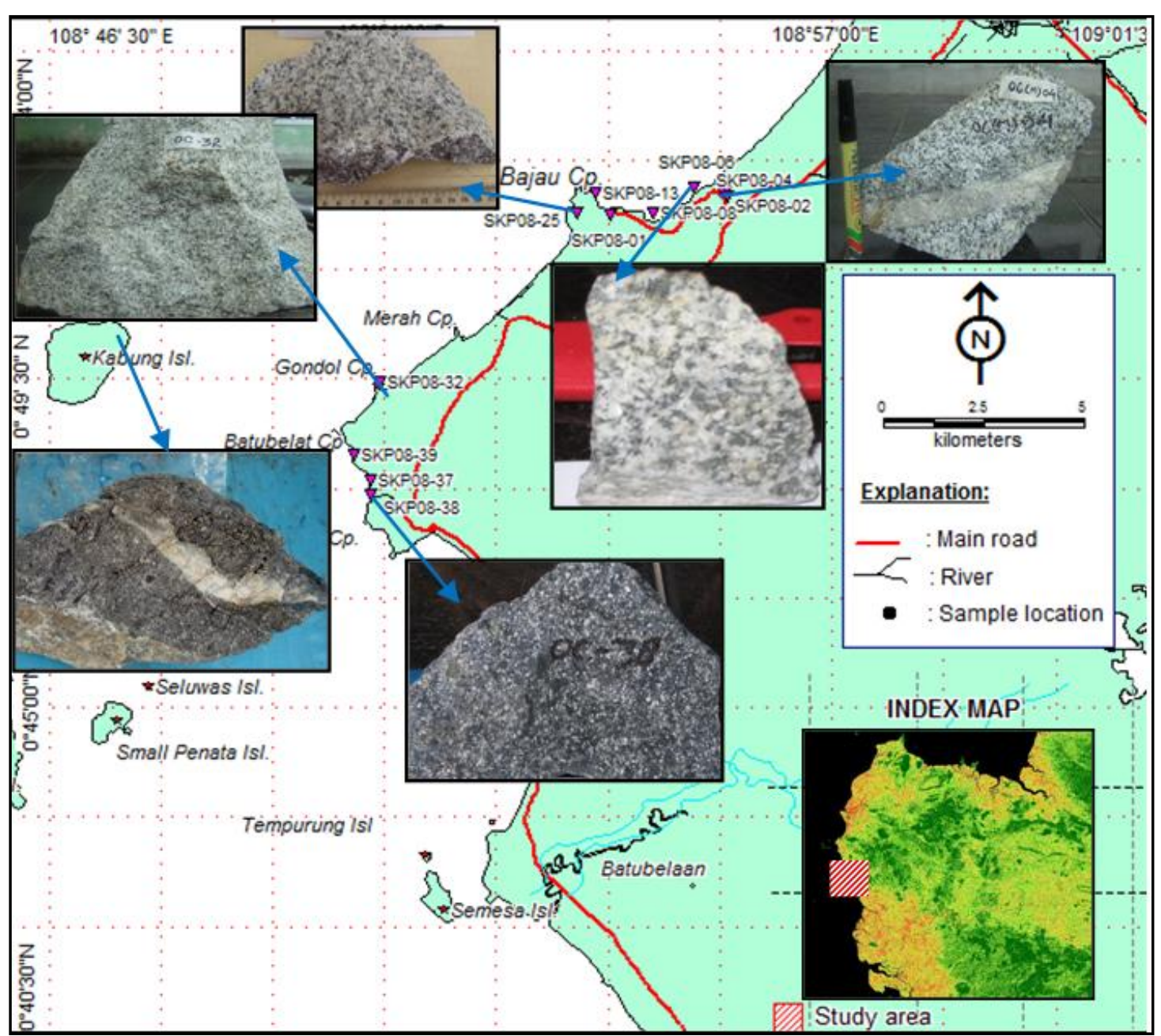

Gambar 2. Peta lokasi penelitian dan pengambilan contoh batuan ${ }^{[7]}$. 


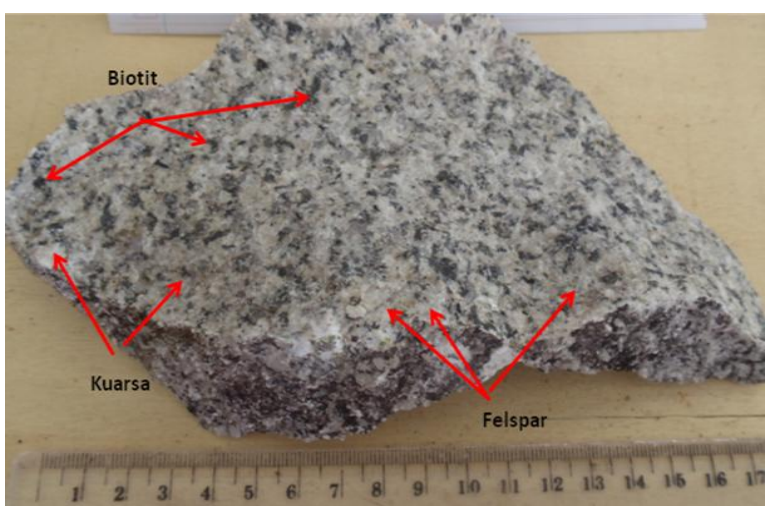

Gambar 3. Batuan granotoid SKP08-04, nampak terlihat kristal mineral felspar, kuarsa, \& biotit berukuran halus-sedang, leucocratic.

Berdasarkan pengamatan sayatan tipis pada analisis petrografi, secara umum dicirikan sebagai holokristalin, fanerik sedang-kasar, bentuk kristal subhedraleuhedral dan hipidiomorfik granular. Contoh nomor SKP08-04 yang diambil di sebelah timur Tanjung Bajau didominasi oleh plagioklas dan K-Feldspar. Plagioklas tidak berwarna, relief rendah, kembaran albit dan kalsbat albit, ukuran mineral 0,3-1,8 mm, bentuk kristal subhedral-euhedral, dengan jenis Albit $\left(\mathrm{An}_{10}\right)$. Mikroklin tidak berwarna, relief rendah, ukuran mineral 0,22-1,4 mm, bentuk kristal subhedral-euhedral. Ortoklas tidak berwarna, relief rendah, ukuran mineral 0,2-1 mm, bentuk kristal subhedral-euhedral, dijumpai sebagian telah terubah menjadi serisit. Kuarsa hadir sebagai butiran yang anhedral dengan ukuran 0,5 sampai 1,6 mm, subhedral, hadir merata dalam sayatan. Biotit terkadang hadir sebagai fenokris, coklat kekuningan-coklat kehijauan, euhedral, pipih dan sedikit berlembar dengan pleokroisme yang tinggi ${ }^{[1]}$. Mengacu pada diagram AQP oleh Streckeisen (1979 dalam Le Maitre ${ }^{[10]}$ ) contoh nomor SKP08-04 adalah monzogranit.

\section{Karakteristik Radioaktivitas}

Berdasarkan hasil analisis unsur radioaktif dengan menggunakan metode gamma spektrometri terhadap tujuh contoh singkapan batuan dan dua contoh sedimen (Tabel 1), terlihat bahwa kandungan gross $\gamma$, $\mathrm{U}_{238}$ dan $\mathrm{Th}_{232}$ tertinggi terdapat di lokasi yang sama, yaitu di sebelah timur Tanjung Bajau (SKP08-04) pada batuan monzogranit, demikian pula aktivitas pancaran $ß$ serbuknya (Tabel 2).

Tabel 2. Hasil analisis unsur radioaktif data aktivitas (Bq/25gr) pancaran ß serbuk.

\begin{tabular}{cccl}
\hline No. & Kode Contoh & $\begin{array}{c}\text { Aktivitas } \beta \\
\text { Gross } \\
(\mathrm{Bq} / 25 \text { gr })\end{array}$ & Keterangan \\
\hline 1 & KB08-01 & $0,273 \pm 0,025$ & Diorit $^{3)}$ \\
2 & SKP08-02 & $0,200 \pm 0,026$ & Tonalit $^{3)}$ \\
3 & BT-02 & $0,118 \pm 0,005$ & pasir $^{2)}$ \\
4 & SKP08-04 & $0,370 \pm 0,010$ & Monzogranit $^{3)}$ \\
5 & SKP08-16B & $0,067 \pm 0,015$ & Granodiorit $^{3)}$ \\
6 & SKP08-25B & $0,118 \pm 0,046$ & altered rock $^{3)}$ \\
7 & SKP08-37 & $0,062 \pm 0,021$ & altered rock $^{3)}$ \\
8 & SKP08-56 & $0,257 \pm 0,031$ & Granodiorit $^{3)}$ \\
9 & SKWL08-24 & $0,298 \pm 0,010$ & Lanau pasiran $^{1)}$ \\
\hline
\end{tabular}

Keterangan:

1)
2) sedimen dasar laut
3) $\quad$ sedimen pantai
$\quad$ singkapan batuan

\section{Karakteristik kimiawi}

Dari beberapa contoh batuan magmatik yang dianalisis pancaran radioaktivitas batuannya, dipilih 4 (empat) contoh batuan yang relatif belum terubah untuk dilakukan analisis kimiawi batuan, dalam hal ini senyawa utamanya (major element) dengan menggunakan metode ICP (Tabel 3). Analisis ini dilakukan untuk mengetahui apakah ada keterkaitan antara konsentrasi pancaran terhadap kandungan kimiawi batuannya. 
Tabel 3. Hasil analisis senyawa batuan.

\begin{tabular}{|c|c|c|c|c|}
\hline $\begin{array}{c}\text { Senyawa } \\
\text { Utama }\end{array}$ & $\begin{array}{c}(1) \\
\text { SKP08- } \\
02\end{array}$ & $\begin{array}{c}(2) \\
\text { SKP08- } \\
25 A\end{array}$ & $\begin{array}{c}(3) \\
\text { SKP08- } \\
16 B\end{array}$ & $\begin{array}{c}(4) \\
\text { SKP08- } \\
04\end{array}$ \\
\hline & Tonalit & $\begin{array}{c}\text { Grano- } \\
\text { diorit }\end{array}$ & $\begin{array}{c}\text { Grano- } \\
\text { diorit }\end{array}$ & $\begin{array}{c}\text { Monzo- } \\
\text { granit }\end{array}$ \\
\hline $\mathrm{SiO}_{2}$ & 60,95 & 65,26 & 68,87 & 69,55 \\
\hline $\mathrm{Al}_{2} \mathrm{O}_{3}$ & 8,48 & 11,22 & 14,88 & 10,63 \\
\hline $\mathrm{Fe}_{2} \mathrm{O}_{3}$ & 14,01 & 8,11 & 4,06 & 5,73 \\
\hline $\mathrm{CaO}$ & 2,50 & 5,16 & 3,39 & 3,88 \\
\hline $\mathrm{MgO}$ & 2,47 & 2,37 & 1,37 & 2,09 \\
\hline $\mathrm{K}_{2} \mathrm{O}$ & 0,65 & 1,79 & 2,16 & 2,69 \\
\hline $\mathrm{Na}_{2} \mathrm{O}$ & 6,50 & 3,10 & 3,69 & 2,85 \\
\hline $\mathrm{MnO}$ & 0,006 & 0,10 & 0,07 & 0,10 \\
\hline $\mathrm{FeO}$ & 1,04 & 1,46 & 0,65 & 1,64 \\
\hline $\mathrm{P}_{2} \mathrm{O}_{5}$ & 0,004 & 0,13 & 0,16 & 0,032 \\
\hline $\mathrm{TiO}_{2}$ & 0,11 & 0,49 & 0,32 & 0,35 \\
\hline $\mathrm{H}_{2} \mathrm{O}$ & 2,11 & 0,82 & 3,21 & 0,45 \\
\hline LOI & 0,01 & 1,32 & 0,69 & 1,14 \\
\hline \multicolumn{5}{|c|}{ Norm CIPW } \\
\hline $\mathrm{Q}$ & 18,55 & 29,72 & 30,28 & 34,39 \\
\hline Or & 4,02 & 10,81 & 12,76 & 16,25 \\
\hline $\mathrm{Ab}$ & 41,79 & 26,23 & 31,22 & 24,62 \\
\hline An & 0,00 & 11,41 & 16,77 & 8,45 \\
\hline Di & 9,81 & 9,58 & 0,00 & 7,89 \\
\hline Hy & 1,88 & 1,61 & 3,41 & 1,65 \\
\hline Mt & 0,00 & 0,00 & 1,36 & 0,00 \\
\hline $\mathrm{He}$ & 9,87 & 5,62 & 3,12 & 5,85 \\
\hline Il & 0,02 & 0,21 & 0,61 & 0,21 \\
\hline Ap & 0,00 & 0,30 & 0,37 & 0,07 \\
\hline Ac & 13,80 & 0,00 & 0,00 & 0,00 \\
\hline $\mathrm{C}$ & 0,00 & 0,00 & 0,69 & 0,00 \\
\hline $\mathrm{Sp}$ & 0,24 & 0,95 & 0,00 & 0,61 \\
\hline $\begin{array}{l}\mathrm{Ca} /(\mathrm{Ca}+\mathrm{Na}) \\
\text { in plagioklas }\end{array}$ & 0,00 & 29,1 & 32,30 & 24,4 \\
\hline $\mathrm{A} / \mathrm{CNK}$ & 0,53 & 0,69 & 1,04 & 0,70 \\
\hline DI & 64,40 & 79,00 & 90,00 & 83,70 \\
\hline
\end{tabular}

Keterangan:

DI: Indeks Diferensiasi Thornton-Tuttle merupakan ratio normatif (kuarsa+albit+nefelin+leusit+kalsit+ sodium karbonat+sodium sulfat) terhadap berat total norm. Rasio ini adalah ukuran dari diferensiasi batuan beku.

Hasil analisis geokimia senyawa utama dan perhitungan normatif CIPW terhadap empat contoh terpilih di lokasi kajian yang disajikan pada Tabel 3. Pada tabel ini memperlihatkan lima contoh yang dianalisis dengan kondisi contoh yang relatif masih segar (belum terlapukan), diketahui dari kandungan unsur habis dibakar (LOI)-nya yang rendah $(<1 \%)$, yaitu berkisar antara $0,01-1,32 \%$. Kandungan silika $\left(\mathrm{SiO}_{2}\right)$ memperlihatkan kisaran antara 60,95\% $69,55 \%$ berat atau dengan rata-rata $66,79 \%$ berat dan semua contoh yang berasal dari daratan Kalimantan magmanya bersifat metaluminous (kekurangan unsur aluminium) ditandai dengan nilai indeks Shand berupa hasil perbandingan molar $\mathrm{A} / \mathrm{CNK}$ atau $\mathrm{Al}_{2} \mathrm{O}_{3} / \mathrm{CaO}-\left(1,25 \times \mathrm{P}_{2} \mathrm{O}_{5}\right)+\mathrm{Na}_{2} \mathrm{O}+\mathrm{K}_{2} \mathrm{O}<$ $1,1^{[11]}$ sedangkan contoh yang berasal dari Pulau Kabung (KB08-01) bersifat peraluminous (kelebihan unsur aluminium) ditandai dengan indeks Shand $>1,1^{[2]}$.

\section{KESIMPULAN}

Batuan dengan pancaran Gross $\gamma$, aktivitas pancaran $B$ serbuk dan kandungan $\mathrm{U}_{238}$ serta $\mathrm{Th}_{232}$ tertinggi dijumpai pada lokasi sebelah timur Tanjung Bajau (SKP08-04) yang berupa batuan monzogranit. Secara petrologi, batuan di lokasi SKP08-04 merupakan batuan granitoid yang belum (sedikit) terubah dengan tekstur holokristalin, fanerik sedang-kasar, bentuk kristal subhedral-euhedral dan hipidiomorfik granular. Secara mineralogi, batuan di lokasi SKP08-04 memiliki dominasi oleh kuarsa, felspar, dan plagioklas yang melimpah. Secara kimiawi, batuan di lokasi SKP08-04 memiliki kandungan $\mathrm{SiO}_{2}$ dan $\mathrm{K}_{2} \mathrm{O}$ tertinggi bila dibandingkan dengan batuan magmatik lainnya di lokasi penelitian demikian pula normatif kuarsa (Q) dan ortoklas (Or).

\section{UCAPAN TERIMA KASIH}

Penulis mengucapkan terima kasih yang tak terhingga kepada Kepala Puslitbang Geologi Kelautan atas dorongan dan motivasinya selama ini; kepada semua 
anggota tim yang telah membantu dalam pengambilan data di lapangan khususnya Saudara Udaya K., H.C. Widi., Deny S., Hananto K., Heryanto, Sugiono, dan rekanrekan lain yang tidak mungkin disebutkan satu persatu.

\section{DAFTAR PUSTAKA}

1. ARYANTO, N.C.D., SUPARKA, E., ABDULLAH, C.I., and PERMANA, H., "The Petrology Characteristic of Granitoid Rock, Singkawang Coast, West Kalimantan", Bulletin of the Marine Geology, 28-1, 13-20, 2013.

2. ARYANTO, N.C.D., SUPARKA, E., ABDULLAH, C.I., dan PERMANA, H, , "Petrologi dan Geokimia Batuan Granitoid di Pantai Sedau, Kalimantan Barat", Jurnal Teknologi Kebumian, ITB Bandung, 2014.

3. HUTCHISON, C. S., "Geology of North-West Borneo", Elsevier, Amsterdam, 2005.

4. HERYANTO, R., WILLIAMS, P.R., HARAHAP, B.H., and PIETERS, P.E., "Geology of the Sintang Sheet Area, Kalimantan”, Geological Research and Development Centre, Bandung, 1993.

5. TANEAN, H., PATERSON, D.W., and MAC ENDHARTO, "Source Provenance Interpretation of Kutei Basin Sandstones and the Implications for the TectonicStratigraphic Evolution of Kalimantan",
In: Proceedings, Indonesian Petroleum Association, 25th Silver Anniversary Convention, 333-345, 1996.

6. SUWARNA, N., SUTRISNO, KEYSER, F. De., LANGFORD, R.P., dan TRAIL, D.S, "Geologi Lembar Singkawang", Puslitbang Geologi, Bandung, 1993.

7. ARYANTO, N.C.D., KAMILUDIN, U., DARLAN, Y., WIDIATMOKO, H.C, KURNIO, H., SETIYA BUDHI, A., SETIADY, D., DEWI, K.T., dan YULINAR, "Laporan Penyelidikan Mineral Kasiterit dan Mineral Ikutannya di Perairan Singkawang, Kalimantan Barat", Puslitbang Geologi Kelautan, Bandung, 2008.

8. BASUKI, K., "Metode Analisa Unsur Radioaktif", Personal Communication, 2007.

9. WENK, H.R., and BULAKH, A., "Minerals Their Constitution and Origin", Cambridge University Press, U.K., 2004.

10. LE MAITRE, R.W.,"Igneous Rocks Classification and Glossary of Terms". 2nd Ed, Cambridge University Press, Utd Kingdom, 2002.

11. BEA, F., FERShTATER, G. B., and CORRETGÉ, L. G., "The Geochemistry of Phosphorus in Granite Rocks and the Effects of Aluminium", Lithos, 29, 43$56,1992$. 